\title{
Our Textbooks are Wrong: How An Increase in the Currency-Deposit Ratio Can Increase the Money Multiplier
}

\author{
Jesse Aaron Zinn \\ Clayton State University
}

October 28, 2017

\begin{abstract}
I show that when deposits are less than bank reserves the money multiplier is increasing in the currency-deposit ratio. This result contradicts textbooks in intermediate macroeconomic theory and money \& banking, which claim that the money multiplier is always decreasing in the currencydeposit ratio. I also propose an alternative framework in which changes in the monetary base and changes in circulating currency always have a negative relationship. This approach explicitly assumes that the monetary base is constant, which is consistent with an analysis focused exclusively on the behavior of private banks and the public.
\end{abstract}

JEL CoDES: A22, E51, G21

Keywords: Money Supply, Monetary Base, Money Multiplier, Deposits, Reserves

\section{Introduction}

The purpose of this paper is to draw attention to an error contained in contemporary intermediate macroeconomic theory and money \& banking textbooks. ${ }^{1}$

\footnotetext{
${ }^{1}$ I also checked several texts at the principles and graduate levels, and I found no such error, as they do not present an analysis of the multiplier akin to what is typically presented at the upper-division undergraduate level.
} 
Figure 1: The money multiplier for M1 in the United States fell below one during the recovery from the recent financial crisis.

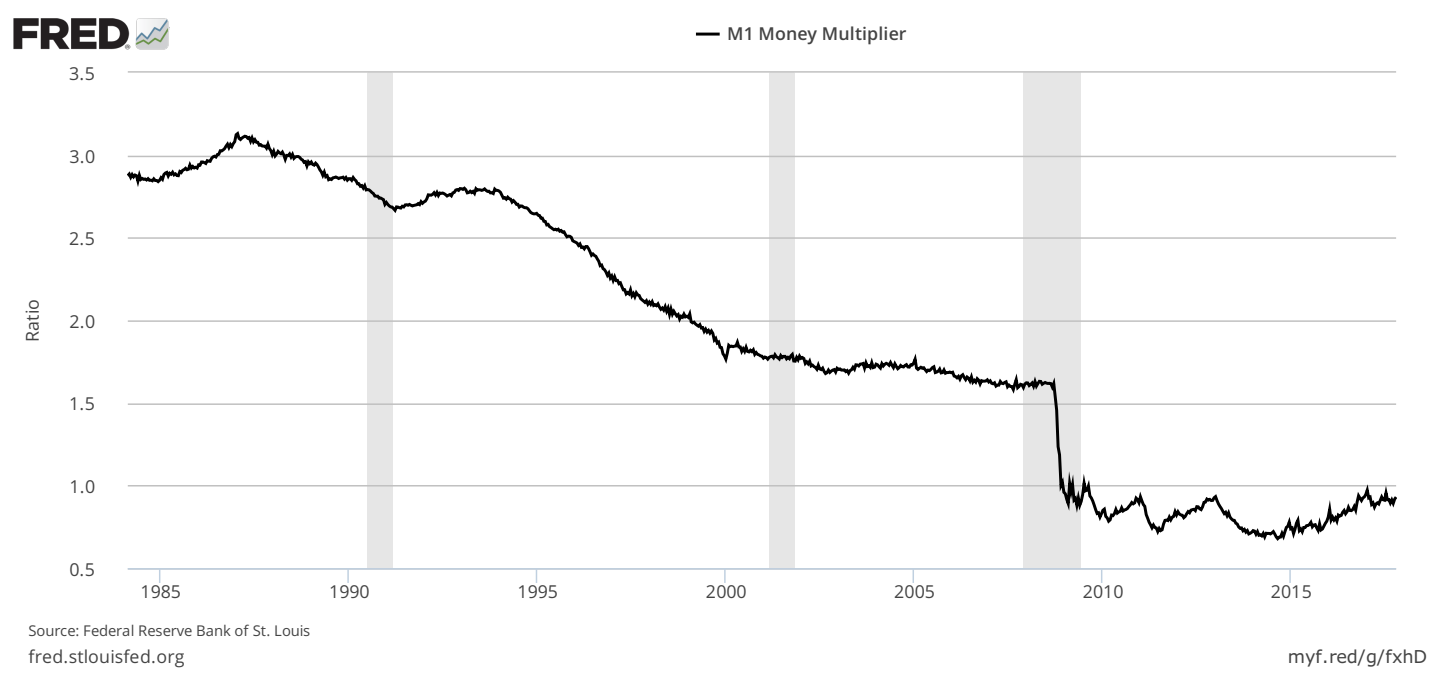

Specifically, I point out that these textbooks mistakenly claim that the money multiplier is unambiguously decreasing in the currency-deposit ratio, by showing that the nature of the relationship reverses when the reserve-deposit ratio is greater than one.

This reversal in the relationship is not merely hypothetical. If the reservedeposit ratio is greater than one the money multiplier is less than one, and this has been the case in the United States for several years, as depicted in Figure 1. The United States finds itself in this curious situation after the financial crisis and subsequent Federal Reserve policies, such as quantitative easing (Joyce, Miles, Scott, and Vayanos, 2012) and interest on reserves (Keister and McAndrews, 2009), have lead to bank reserve levels greater than those of deposits.

I present a version of the textbook framework and highlight the error in Section 2. I go on in Section 3 to propose an alternative framework based on the fact that the monetary base is not affected by changes in the monetary decisions of banks and the public. Using this framework I show that, holding the monetary 
base constant, there is a non-positive relationship between changes in the money multiplier and changes in circulating currency.

\section{A Textbook Analysis of the Money Multiplier}

This section contains an analysis of the money multiplier similar to what can be found in widely-used textbooks on intermediate macroeconomic theory or money \& banking.

Let $\mu$ denote the money multiplier at any given point in time. If $M$ measures the money supply and $B$ is the monetary base then, by definition, $\mu:=M / B$. The money supply consists of both bank deposits $D$ and circulating currency $C$, while the monetary base consists of bank reserves $R$ and currency, so $M=C+D$ and $B=C+R$. Therefore, we can also calculate the multiplier by

$$
\mu=\frac{C+D}{C+R}
$$

Following in the footsteps of Friedman and Schwartz (1963), the lesson goes on to analyze to relationships between the money multiplier and certain ratios of $D, C$, and $R$. Denote the currency-deposit ratio by $c:=C / D$ and the reserve ratio by $r:=R / D$. Then we can finally write

$$
\mu=\frac{c+1}{c+r}
$$

Friedman and Schwartz (1963) defend their focus on such ratios with claims such as, "what the banking system as a whole controls is neither deposits nor reserves alone but rather the ratio of deposits to reserves" (p. 786, emphasis in original) and "we express the public's desires in terms of the ratio of deposits to currency 
rather than in terms of the absolute magnitudes of the components, because it is the ratio that the public as a whole controls" (p. 788, emphasis in original).

It is in analyzing the comparative statics of the relationship in expression (1) where our textbooks contain an error. Before getting to the error, observe that these analyses correctly discuss how the money multiplier is decreasing in the reserve ratio. This is verified by observing that

$$
\frac{\partial \mu}{\partial r}=-\frac{c+1}{(c+r)^{2}}<0
$$

since $c \geq 0$. The intuition behind this result is that a decrease in the reserve ratio necessarily implies that banks are holding a greater proportion of deposits as reserves rather than lending them out. Less lending implies a lower money supply and, thereby, a lower money multiplier.

Our textbooks go on to claim that the money multiplier is also strictly decreasing in the currency-deposit ratio. Consider, for example, the following quotes:

1. "...a decrease in the currency-deposit ratio raises the money multiplier and the money supply" (Mankiw, 2003, p. 487).

2. "The rise in $c$ results in a decline in the overall level of multiple deposit expansion, leading to a smaller money multiplier and a decline in the money supply..." (Mishkin, 2010, p. 368)

But these statements are not necessarily true, as

$$
\frac{\partial \mu}{\partial c}=\frac{r-1}{(c+r)^{2}}
$$

which has the same sign as $r-1$. In a fractional reserve system, banks reserves 
are typically less than deposits, so $R<D$ implying that $r<1$ and $\partial \mu / \partial c<0 .^{2}$ However, with the recent financial crisis and the ensuing policies that have been implemented to mollify its effects, bank reserves in some economies have swelled beyond deposits, resulting in a situation in which $r>1$ so that $\partial \mu / \partial c>0$ while $\mu<1,{ }^{3}$ contrary to the statements made in our textbooks.

It is counterintuitive that an increase in the currency-deposit ratio could ever result in a larger money multiplier. After all, the money supply can only grow larger than the monetary base with bank lending, and if people hold more currency and less deposits then banks have less reserves to lend. Counterintuitive though it may be, this occurs because currency is included in both the money supply and the monetary base, so increasing currency-deposit ratio adds equally to both the numerator and the denominator of the right-hand-side of expression (1), thereby dampening the effect of the ratio $1 / r$ that constitutes the part of the expression that does not include the currency-deposit ratio. Such dampening forces the multiplier closer to one, whether from above or below.

\section{An Alternative Framework}

The results in the previous section raise the question: Is there a way to capture the idea that people holding more currency leads to a lower (or at least unchanged) money multiplier, regardless of the magnitude of reserves relative to deposits? The problem with the traditional approach is that simply analyzing how the multiplier changes due to a change in $c$ (or $C$, as discussed in footnote 2), while holding other variables constant, does not capture the relations and dynamics of the variables

\footnotetext{
${ }^{2}$ The issue with $\partial \mu / \partial c$ occurs also with $\partial \mu / \partial C=(R-D) / B^{2}$, as they necessarily have the same sign.

${ }^{3}$ Note also, from expression (1), that $r>1$ implies $\mu<1$, so the money supply is actually less than the monetary base.
} 
as they change.

Rather than focusing on how the money multiplier is affected by changes in one variable (or one ratio of variables) at a time, I propose an analysis designed specifically to answer the following question: In an economy with given levels of $C, B$, and $D$, how would the multiplier change if the public held a different level of circulating currency, holding the monetary base constant?

We focus on cases in which the monetary base is unchanged because in our textbook analysis we are interested in the effects of changes in the behavior of the public and banks, whose financial transactions (e.g. making loans, deposits, or withdrawals) cannot change the magnitude of the monetary base. Control of the monetary base falls to the central bank (or to those in the business of extracting or manufacturing a commodity that functions as money).

Of course, if the $B$ is held constant, a change in the level of $C$ necessitates a change in $R$ of equal magnitude in the opposite direction. Suppose in one scenario the respective levels of circulating currency, bank reserves, and deposits are $C_{0}$, $B_{0}$, and $D_{0}$. Now let us compare this baseline with another scenario in which the monetary base is unchanged, while the public holds $C_{0}+\Delta C$ units of currency, deposits are $D_{0}+\Delta D$, and bank reserves are $R_{0}+\Delta R$ in equilibrium, after the multiplier process is exhausted. Since the monetary base is identical in the two scenarios, we must have

$$
\Delta R=-\Delta C
$$

The change in the level of deposits $\Delta D$ depends on economic conditions, as well as the liquidity preferences and beliefs of the public and banks. We can captures these conditions and preferences by defining a parameter we might call the marginal reserve ratio, $\rho:=\Delta R / \Delta D$. Combining this with expression (2) 
yields

$$
\Delta D=\Delta R / \rho=-\Delta C / \rho
$$

Let $\Delta \mu$ be the difference between the values of the money multiplier in the two scenarios:

$$
\Delta \mu:=\frac{C_{0}+D_{0}}{C_{0}+R_{0}}-\frac{C_{0}+\Delta C+D_{0}+\Delta D}{C_{0}+\Delta C+R_{0}+\Delta R}
$$

Expressions (2) and (3) imply that the multiplier in the second scenario is

$$
\frac{C_{0}+\Delta C+D_{0}+\Delta D}{C_{0}+\Delta C+R_{0}+\Delta R}=\frac{C_{0}+\Delta C+D_{0}-\Delta C / \rho}{C_{0}+R_{0}} .
$$

Therefore, after combining expressions (4) and (5), we find that

$$
\Delta \mu=\frac{\Delta C}{C_{0}+R_{0}}\left(1-\frac{1}{\rho}\right)
$$

Banks generally hold reserves so that they can meet the withdrawal demands of depositors. Such behavior on the part of the banking system suggests that any increase in deposits coincides with an increase in reserves (or vice versa), implying $\rho>0 .^{4}$ Given that we are abstracting from any actions from central banks, we would not expect the change in reserves to be larger than the change in deposits, ${ }^{5}$ thus $\rho \leq 1$. To summarize, we assume $\rho \in(0,1]$.

From expression (6) it is clear that

$$
\rho \in(0,1) \quad \Longrightarrow \quad \frac{\Delta \mu}{\Delta C}<0
$$

\footnotetext{
${ }^{4}$ If banks are reserve-constrained in either scenario and there is a constant required reserve ratio then $\rho$ is greater than or equal to that ratio. Equality holds between $\rho$ and the required reserve ratio if banks are reserve-constrained in both scenarios.

${ }^{5}$ If banks in aggregate obtain reserves either from a central bank or from deposits and central banks are not a source then a change in reserves must be from a change in deposits, in which case the former can be no larger than the latter.
} 
from which we can conclude that as long as banks lend out some of their additional reserves (in whichever scenario has more reserves) then there is a negative relationship between changes in circulating currency and the money multiplier.

And when the change in reserves is equal to the change in deposits we have

$$
\rho=1 \quad \Longrightarrow \quad \frac{\Delta \mu}{\Delta C}=0 .
$$

Thus, when banks do not lend any more or less between the two scenarios the multiplier is unchanged, regardless of the value of $\Delta C$.

The conjunction of expressions (7) and (8) yields the conclusion that if consumers hold more currency then, holding the monetary base constant, the money multiplier should not increase. This contrasts with the textbook analysis presented in the previous section which shows that when the money multiplier is less than one increases in currency or in the currency-deposit ratio yield an increase in the money multiplier.

\section{Conclusion}

I have shown that our textbooks erroneously claim that the money multiplier is always decreasing in the currency-deposit ratio. The error is specific to cases in which the reserve-deposit ratio is greater than one (which coincide with cases where the money multiplier is less than one).

I also propose an alternative framework that shows when the monetary base is held constant there is always a non-positive relationship between changes in circulating currency and the money multiplier. This result is true no matter what the values of the reserve-deposit ratio or the money multiplier are. 
The constant monetary base assumption, which is key to the framework I propose herein, is justified in this context because we are interested in how changes in variables that the public and private banks jointly control, and their financial choices do not affect the monetary base. By assuming a constant monetary base we are essentially extrapolating from any changes in monetary policy, since it is the monetary authority which determines the level of any monetary base.

\section{References}

Friedman, M., and A. J. Schwartz (1963): A Monetary History of the United States, 1867-1960. Princeton University Press.

Joyce, M., D. Miles, A. Scott, and D. Vayanos (2012): "Quantitative Easing and Unconventional Monetary Policy-An Introduction," The Economic Journal, 122(564), F271-F288.

Keister, T., and J. J. McAndrews (2009): "Why Are Banks Holding So Many Excess Reserves?," Current Issues in Economics and Finance, 15(8), 110.

Mankiw, N. G. (2003): Macroeconomics. Worth Publishers.

Mishkin, F. S. (2010): The Economics of Money, Banking, and Financial Markets. Addison-Wesley. 